$$
\begin{aligned}
& \text { بروسى تخيير ات ريختشناختى زالزالكى تحت تأثير برخى عوامل اقليمى در ايران }
\end{aligned}
$$

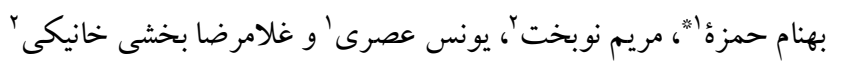

$$
\begin{aligned}
& \text { دريافت: } \\
& \text { 'مؤسسة تحقيقات جنكالها و مراتع كشور، سازمان تحقيقات، آموزش و ترويج كشاورزى، تهران، ايران }
\end{aligned}
$$

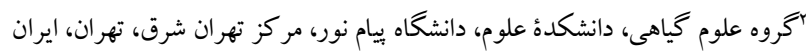

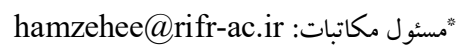

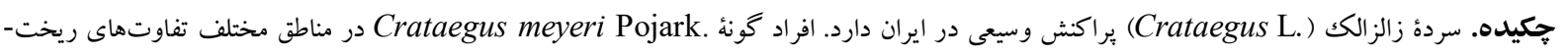

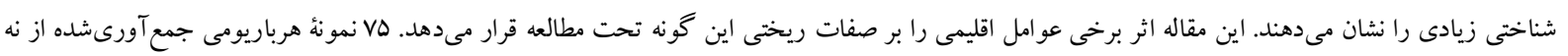

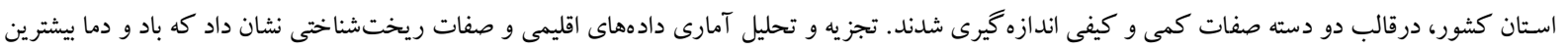

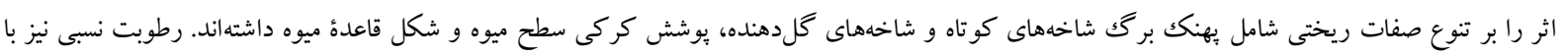

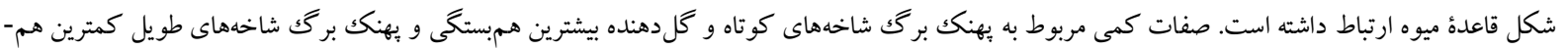
بستخى آمارى با دادههاى اقليمى نشان دادهاند.

وازههاى كليدى. آسياى جنوب غربى، بومشناسى، توع، كل سرخيان، همبستى

\title{
Evaluation of morphological changes of Crataegus meyeri Pojark. in relation to some climatic parameters in Iran
}

\author{
Behnam Hamzeh'ee ${ }^{1 *}$, Maryam Nobakht ${ }^{2}$, Younes Asri ${ }^{1} \&$ Gholamreza Bakhshi Khaniki ${ }^{2}$ \\ Received 08.10.2017/ Accepted 31.12.2017/Published 19.03.2018
}

${ }^{1}$ Research Institute of Forests and Rangelands, Agricultural Research, Education and Extention Organization (AREEO), Tehran, Iran

${ }^{2}$ Botany Department, Faculty of Science, Payame Noor University, Tehran, Iran

*Correspondent author: hamzehee@rifr-ac.ir

\begin{abstract}
The genus Crataegus L. has a wide distribution in Iran. Induviduals of Crataegus meyeri Pojark. show morphological variations in different regions. In this research, the effects of climatic variations on morphological traits of $C$. meyeri were studied. Seventy five specimens collected from nine provinces of Iran were measured in two sets of quantitative and qualitative traits. Statistical analysis of climatic data and morphological traits showed that wind and temperature were the most effective factors affecting the variety of morphological traits including leaf blade of short shoot and flowering shoot, indumentum of fruit surface and fruit shape. Relative humidity has also been correlated with the shape of the fruit base. Quantitative traits of leaf blade of short shoots and flowering shoots showed the highest correlation and leaf blade of elongate shoots with the least statistical correlation with climatic data.
\end{abstract}

Keywords. correlation, ecology, Rosaceae, south west Asia, variation 
يكى از گونههاى سرده زالزالكك با بيشترين تغييرات ريخت-

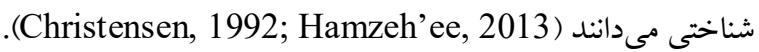

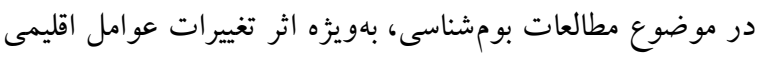
بر جندشكلى صفات مورفولوزيكى C. meyeri، تحقيق زيادى در دست نيست. با اجراى اين تحقيق اثر عوامل اقليمى بر صفات ريختى اين گونه مشخص شد.

\section{مواد و روشها} ابتدا ... نمونه، كه از قبل با نام Crataegus meyeri در هرباريوم مركزى ايران (TARI) و هرباريوم مركزى دانشكاه

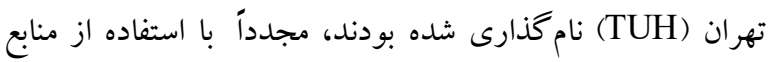
Pojarkova, 1939; Riedl, 1969; ) كياهشناسى موجودان Christensen, 1992; Khatamsaz, 1992; Hamzeh'ee,

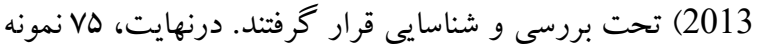
با نام گونه

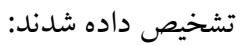
مازندران: سياهبيش، شيبهاى شمالى، ...r متر، خاتمساز و

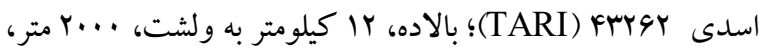

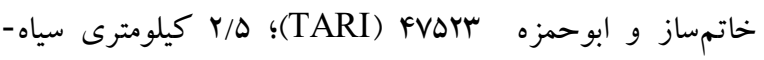

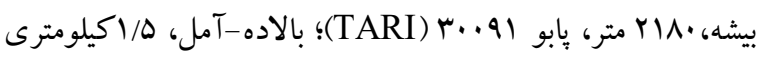

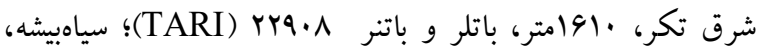

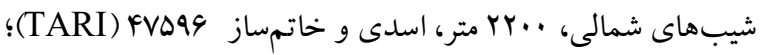

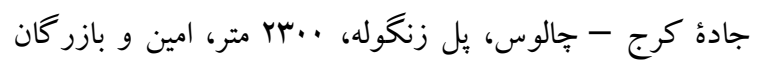
(TARI) (TARو)؛ نوشهر، جنگل خيرود كنار، شيروانى و اعتماد (TARI 9 9VYV

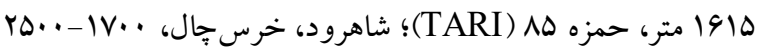

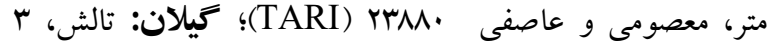

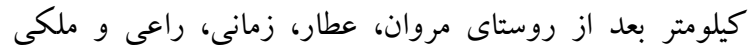
(TUH) F.Fkr اردييل: س كيلومتر از هشتجين به خلخال، ...

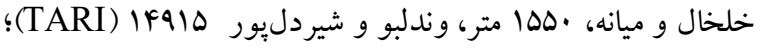

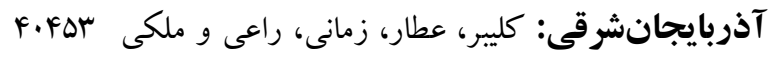

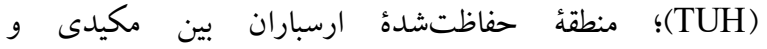
كليبر،..Vامتر، اسدى و وثوقى حفاظتشدة ارسباران، شمال شرق مكيدى، ..هامتر، رونهماركى
مطالعات بومشناختى نشان داده است كه ويزگى بسيارى از

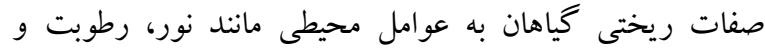

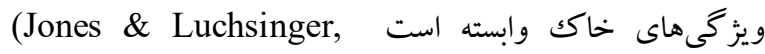
(1979. زالزالكك درختى نوريسند است كه در محيطهاى بوم واسته

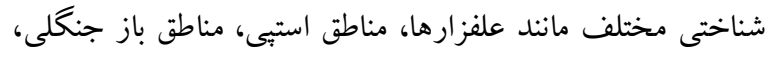

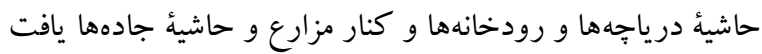

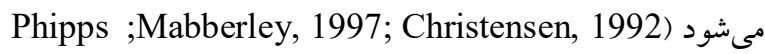
א \&uniyamma, 1980 \& اين سرده، براكنش وسيعى در دنياى قديم و دنياى جديد دارد. مر كز تنوع بخشه Crataegus در تر كيه

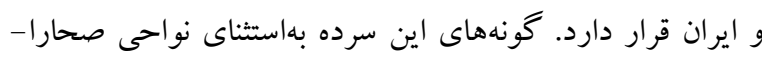
سندى، در نواحى رويشى ارويا- سيبرى (حوزه هير كانى)، ايرانو -

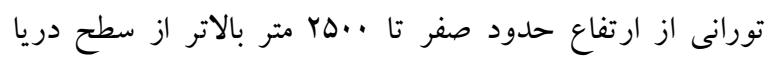
يراكنش دارند (Hamzeh'ee, 2013; Christensen, 1992). امروزه، بازنخرى هاى سيستماتيكى و تحقيقات بيوسيستماتيكى (بروبى

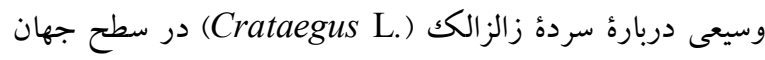

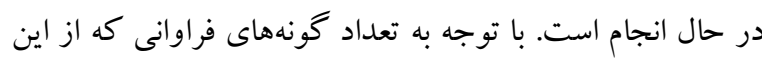

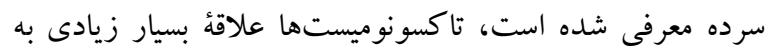

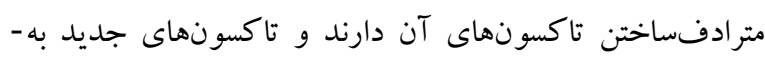

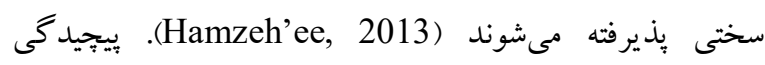

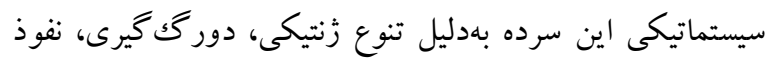

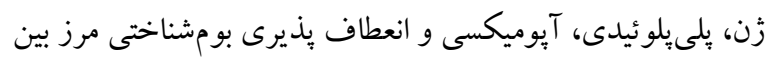

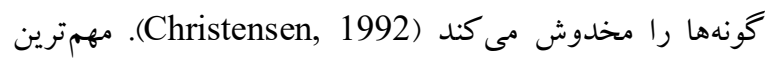
صفات ريختى كه در تفكيك گونهها به كار مىرود شامل حضور

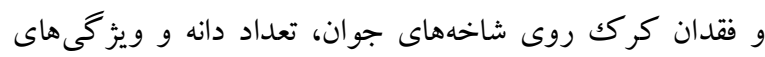

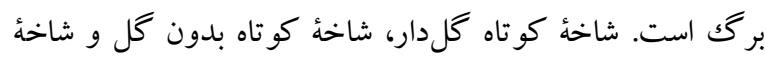

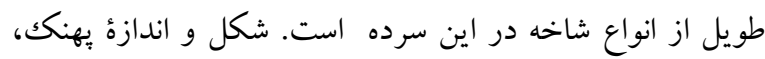

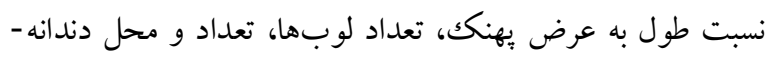

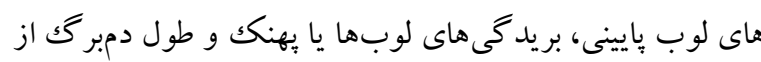

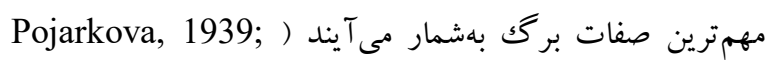

.(Christensen, 1992; Hamzeh'ee, 2013 Crataegus meyeri Pojark.

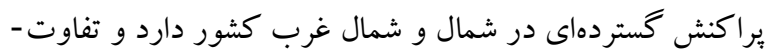

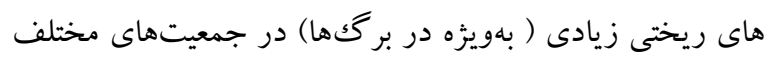

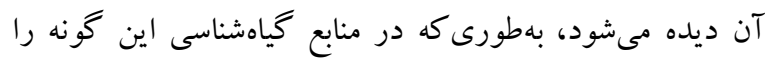


بانى، قبل از روستاى سوربان، MOF متر، حمزه، عطار، زمانى و قاسميور · بrUH, TARI) (TUH)؛ اروميه، جاده انهر، بعد از روستاى شيخ شمزين به سوليك،، •199 متر، حمزه، عطار، زمانى و قاسميور سसrMT) (TUH, TARI)؛ سردشت به بيرانشهر، كيلومتر

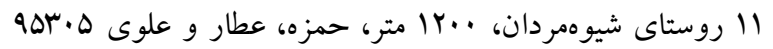
(TUH, TARI)؛ سردشت به بيرانشهر، كيلومتر 11 روستاى

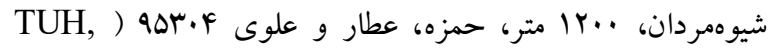
TARI

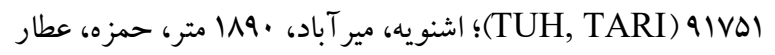
و علوى · اسهو (TUH, TARI)؛ اشنويه، مير آباد، . 19 متر، حمزه، عطار و علوى TUH, TARI) 9 (TUVV) اشنويه، مير آباد، 19. متر، حمزه، عطار و علوى سهرهو (TUH, TARI)؛ اشنويه، مير آباد، . .19H, متر، حمزه، عطار و علوى (TARI (TUH, TARI) اشنويه، مير آباد، .19 متر، حمزه، عطار و علوى TUH, TARI (TUM)؛ اروميه، مارميشو، جاده اصلى

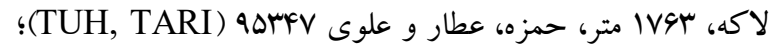
كردستان: ها كيلومترى بانه به سنندج، مسير نكروز، اطراف روستاى ميرده، .109 متر، حمزه، عطار، علوى و معروفى $90 Y 9 \Delta$ (TUH, TARI)

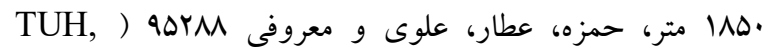
(TARI

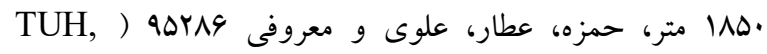
(TARI TUH, ) متر، حمزه، عطار، زمانى و معروفى سM MFA

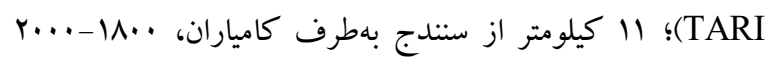

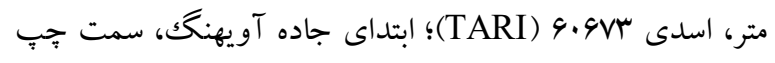

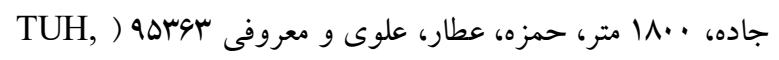
(TARI

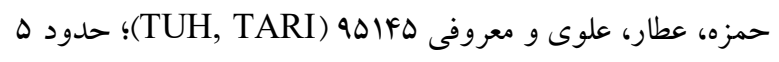
كيلومتر از سه راه آويهنگ بهطرف سنداج، روستاى خوشاب، حمزه، عطار، علوى و معروفى ·ب (TUH, TARI)؛ حدود هـ كيلومتر از سهراه آويهنگك بهطرف سندج، روستاى خوشاب، حمزه، عطار، علوى و معروفى هو (TUH, TARI)؛ لرستان:

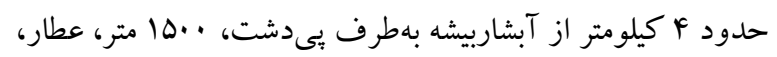

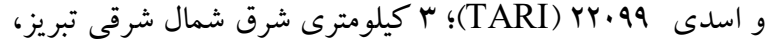

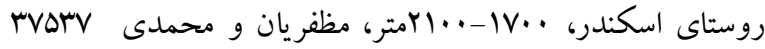

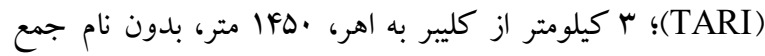

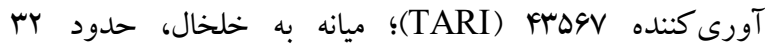

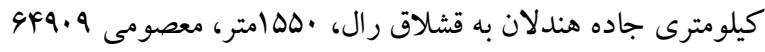

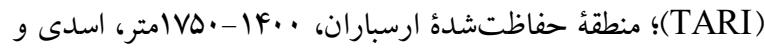
معصو مى TARI) Y. I TV)؛ منطقة حفاظتشده ارسباران، غرب

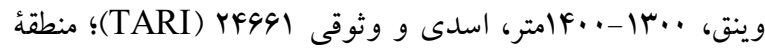

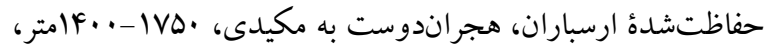

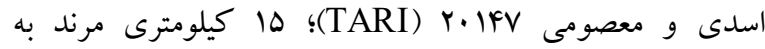

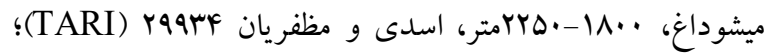
آذربايجانغربى: ه كيلومترى اروميه بهطرف بانه، زهزاد ب.r.r (TARI)؛ اشنويه، مير آباد، .119 متر، حمزه، عطار و علوى

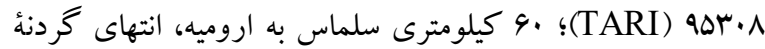

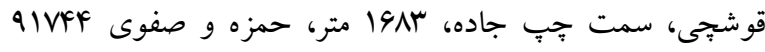

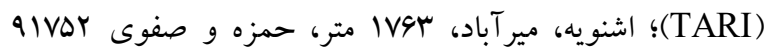
(TARI)؛ · •4 كيلومترى سلماس به اروميه، س191 متر، حمزه و صفوى هو 91 (TARI)؛ ، •4 كيلومترى سلماس به اروميه، انتهاى

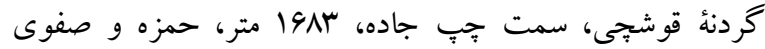

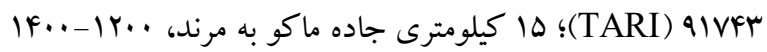
متر، اسدى و مظفريان سشا •ץ (TARI)؛ F كيلومترى قطورخوى، صيامى سبr • r (TARI)؛ اروميه، برده سو سيلوانا، زهز اد و

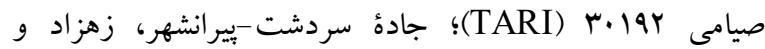

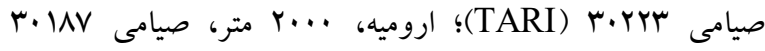
(TARI)؛ . سكيلومتر تا بانه . .هامتر، زهزاد و صيامى بدون شماره (TARI) (TARI) اشنويه، ميراباد، 119امتر، حمزه و صفوى TARI) 9IVF9؛

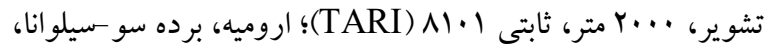

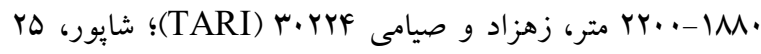
كيلومترى جاده اروميه، · · IVY) متر، فروغى 1.9VI) (TARI)

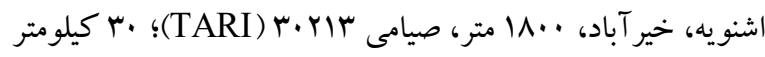

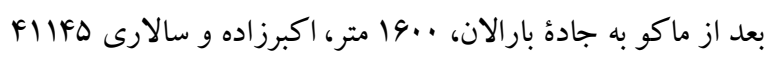

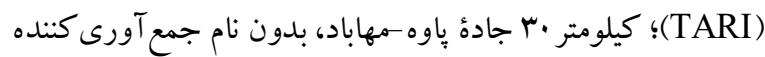

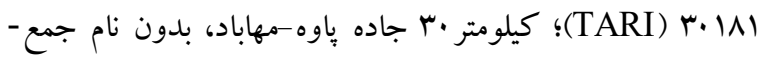

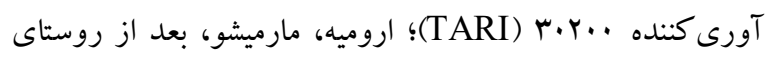


تاكسونوميكى جهت تفكيك گونهاى مختلف زالز الكك است. طبق اين نتايج، بيشترين صفات ريختى با دادههاى مربوط به به باد

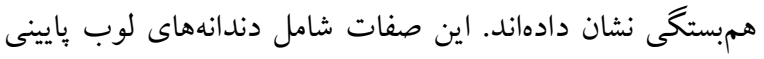

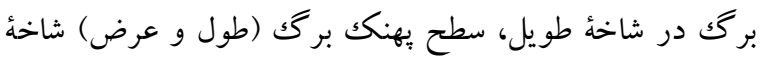

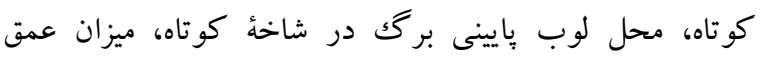

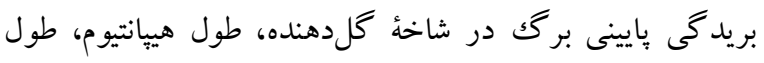

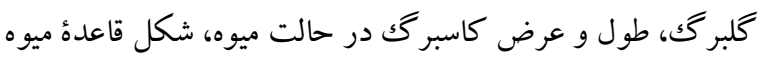

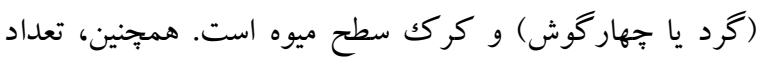

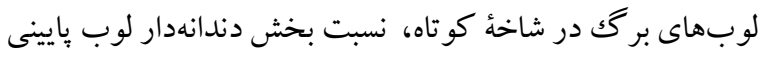

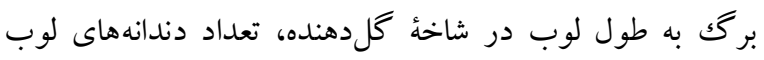

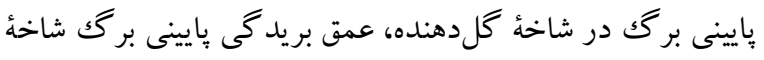

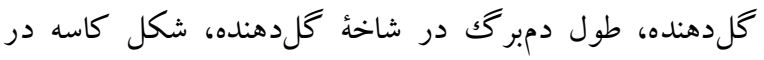

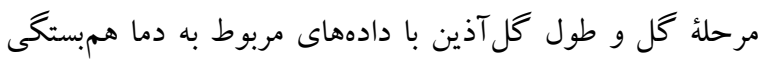

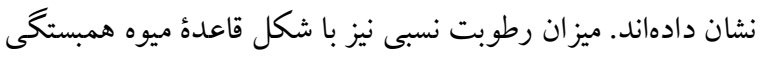

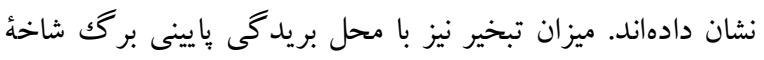

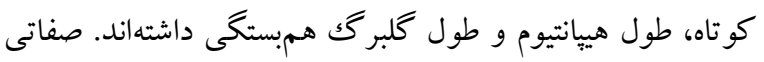
كه هيج گونه همبستكى آمارى با دادههاى اقليمى نداشتهاند شامل

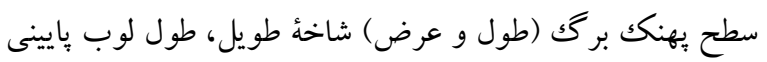

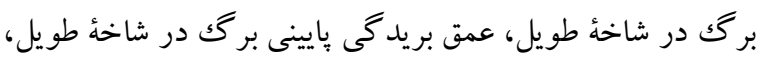

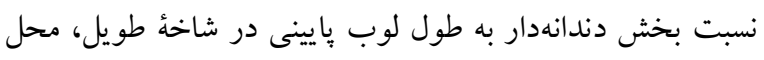

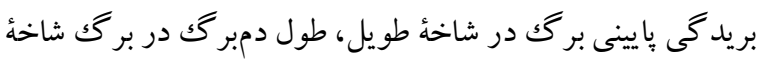

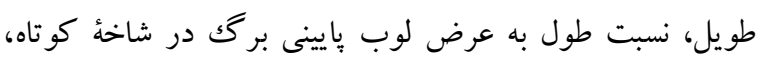

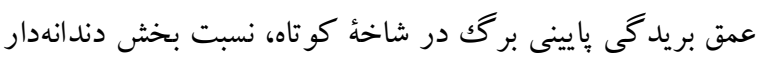

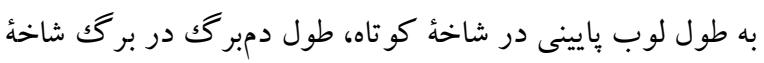

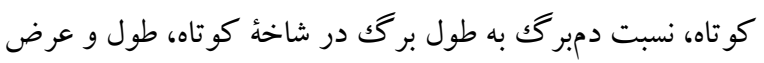

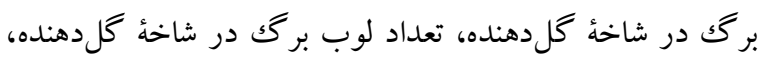
نسبت طول به عرض لوب بايينى برگك در شاخه كلدهنده، محل

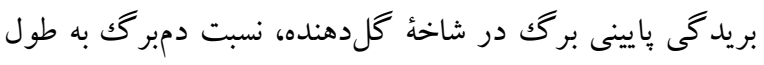

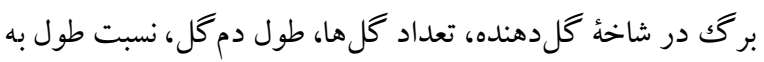

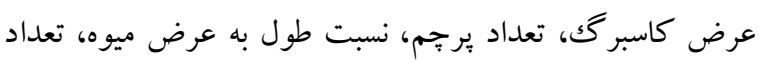

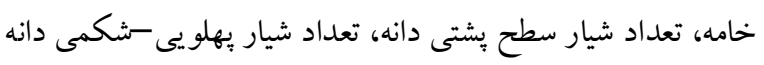
و شكل كلى ميوه هستند.

\section{بحث و نتيجه كيرى}

مشخصات ريختى برگك و بررسى ميز ان تغييرات آن در محيطهاى

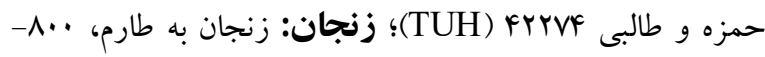

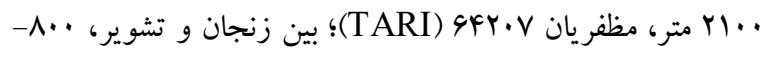

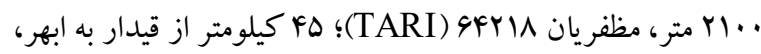

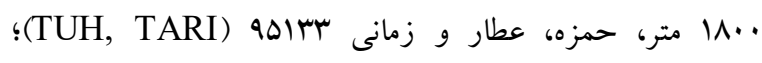

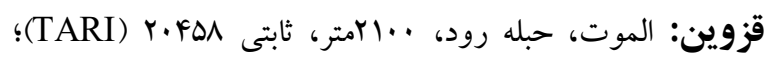

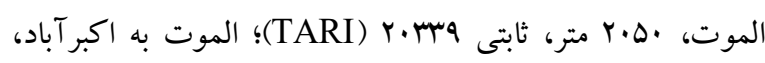

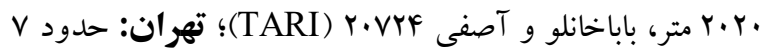
كيلومتر به كندوان، •YYA

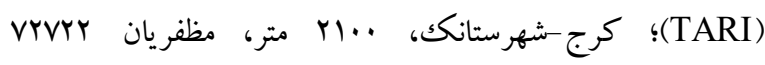
(TARI)

نقشهُ براكنش اين گونه در ايران بر اساس نشانىهاى مربوط به

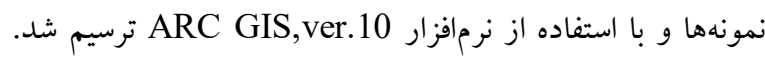
بهمنظور اندازهيرى صفات ريختشناختى گونهُ مورد نظر،

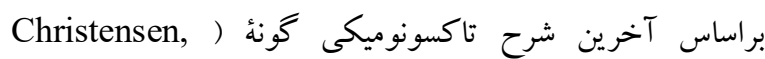

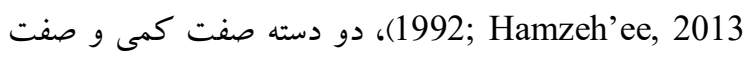
كيفى د نظر كرفته شد (جدول ()). صفات كمى بلهوسيلة لو دستى در مقياس ميلىمتر ثبت شد. اطلاعات اقليمى استانهاى تحت مطالعه در دورههاى ·1 تا ·م ساله (برحسب اطلاعات

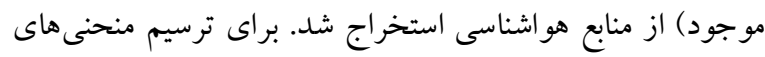

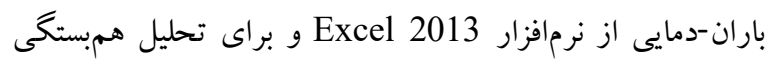

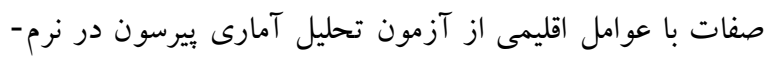
افزار SPSS ver. 17 استفاده شد.

نتايج نقشهٔ براكنش نمونهاى بررسى شدة

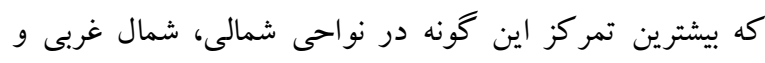

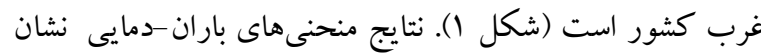

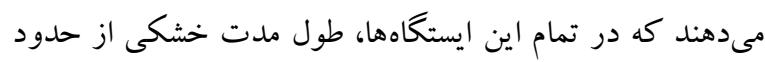

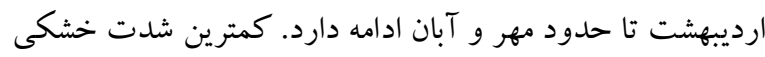

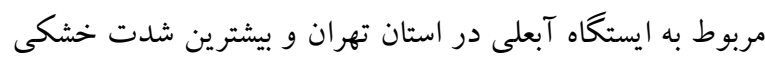

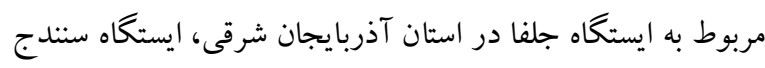

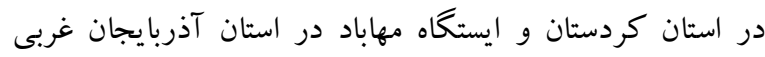

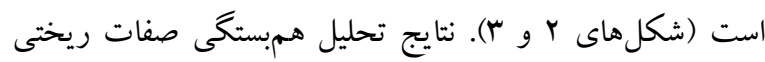

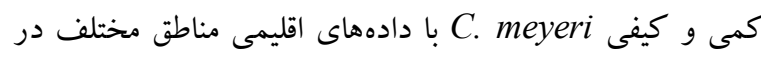
جدول ا آمده است. اين صفات مهمترين و بيشترين صفات 


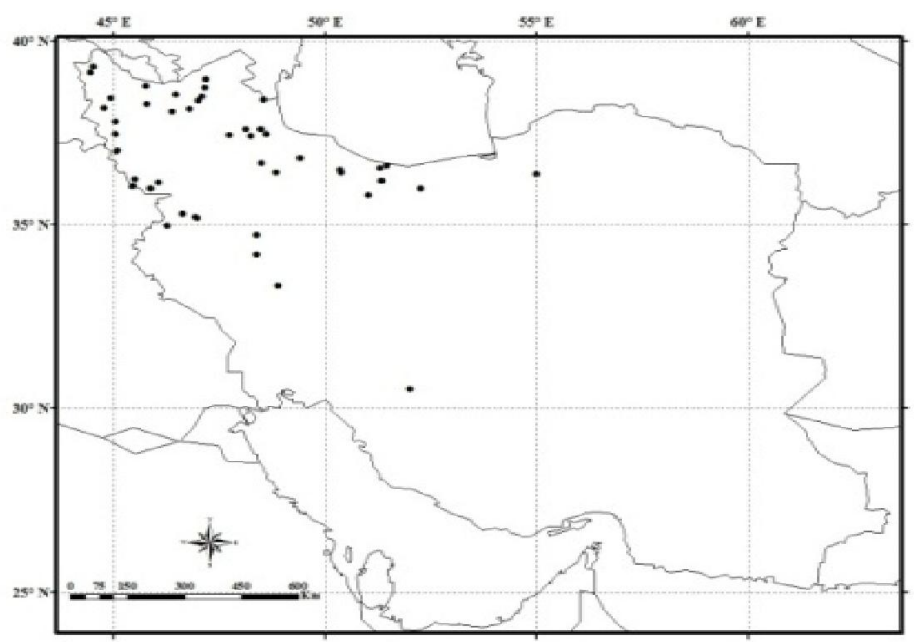

شكل ا- نقشَُٔ يُراكنش C. meyeri در ايران.

Fig. 1. Distribution map of C. meyeri in Iran.

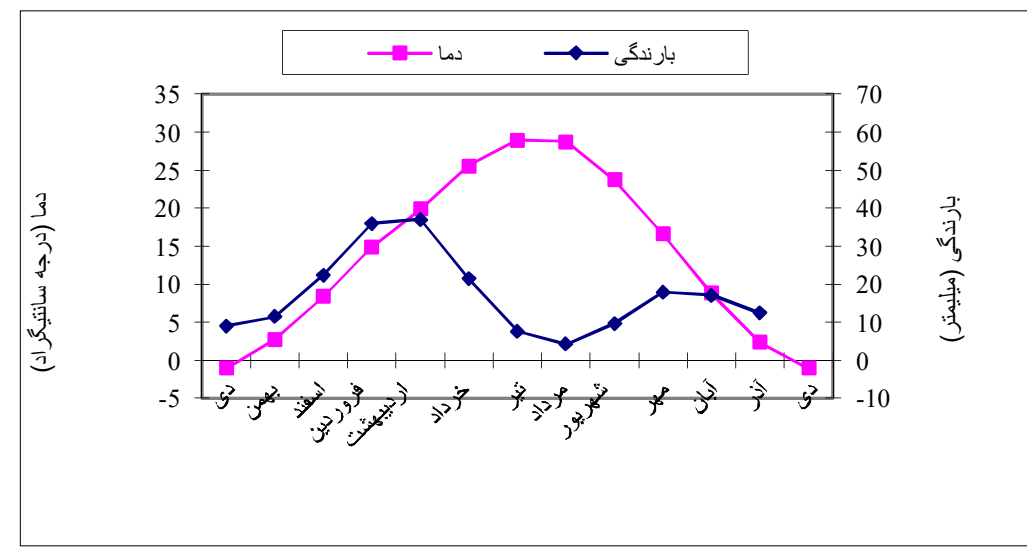

شكل r- منحنى باران دمايى ايستكاه آبعلى.

Fig. 2. Ombrothermic diagram of Abe-Ali station.

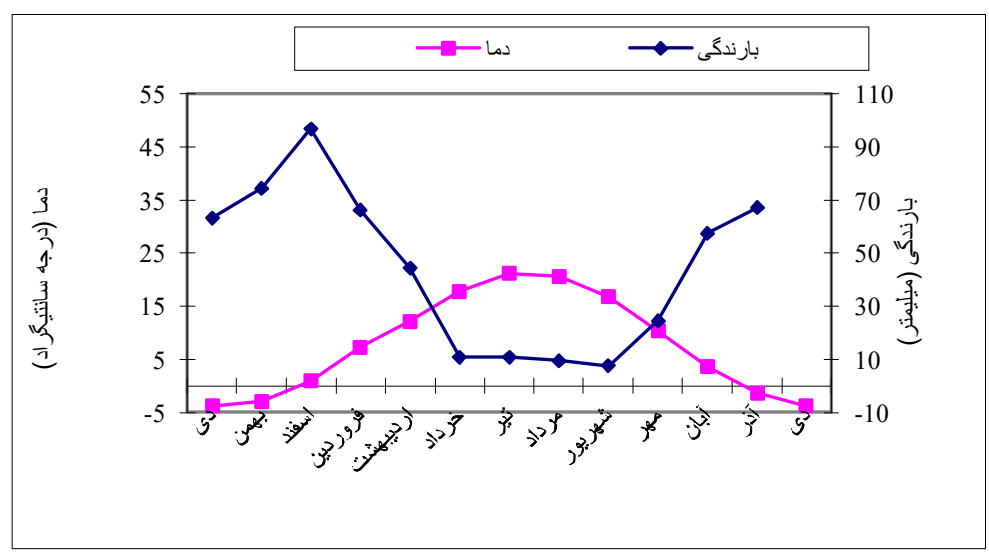

شكل r- منحنى باران دمايى ايستخاه جلفا.

Fig. 3. Ombrothermic diagram of Jolfa station. 
جدول ا-نتايج همبستى صفات ريختى كمى و كيفى C. meyeri با دادههاى اقليمى.

Table 1. Correlation of qualitative and quantitative morphological characters with climatological data.

\begin{tabular}{|c|c|c|c|c|c|c|c|c|c|c|c|c|}
\hline تبخير & 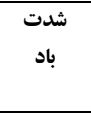 & 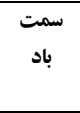 & سباد & بارندتى & يخبندان & نسبي & مطيشينه & مطلق & بيشينه دما & كمينانكين & سالانه & \\
\hline & & & & & & & & & & & & صفات كمى \\
\hline$\% / \cdot 1 \mathrm{~V}$ & $\cdot / \cdot 19$ & $\% r$ & $\cdot / \mathrm{Tr}$ & $\cdot / \pi r$. & .1 .99 &.$/ .19$ & $-\cdot / \mathrm{rVa}$ & $\% \cdot \Delta \Delta$ & $-\cdot / \cdot r$ & -.1 .94 & $-\cdot / / Y \wedge$ & طول برَّك در شاخة طويل \\
\hline ./MT & $\cdot \pi \cdot \Delta$ &.$/ 94$ & 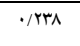 & ./ITY &.$/ r F 9$ & $\% / .99$ & $-\cdot / 1 .+4$ & $\% \cdot \% q$ & $-\cdot / \mathrm{TV}$ & $-0 / / \mathrm{V} 9$ & $-8 / / 999$ & عرض بركَ در شاخة طويل \\
\hline$\cdot / \cdot M$ &.$- / \cdot 1 r$ & . MTYF & $-\cdot / / r r$ & .1 .91 &.$/ Y A F$ & $-\cdot / 11 r$ & $\cdot / \wedge$ & $-\because / / F \mathrm{~V}$ &.$- / . \times 9$ & $-\because / r \Delta 9$ & $-\cdot / / 94$ & طول لوب بايينى بركى در شاخدُ طويل \\
\hline$-\cdot / 111$ & $-* \cdot \wedge r$ & 1.91 & $-0 / .+\%$ & $-\% / \% 4$ & . $/ Y Y Y$ & D & $-\% / .9 r$ &.$/ N \mathrm{TV}$ & $-0 / .91$ & $-\cdot / r \mid r$ & $-\cdot /$ TV9 & بركث در شاخهُ طويل بل عرض بو بايينى \\
\hline$\%+r$ &.$/ .1$ & $-\because / \cdot \wedge f$ & .1 .99 & $-\cdot / 1 \cdot r$ & $\% \Delta r$ & $\cdot / / r 1$ &.- .1 .91 &.$/ r 11$ & $-\cdot / / V F$ & $-\cdot / 1 \cdot 9$ & $-\cdot / 191$ & عمق بريد گى بايينى بركى در شاخه طويل \\
\hline$-\because / \% F$ & $\% \Delta f$ &.$/ 10$. & $--1 / 199$ & $-\cdot / 199$ & $-\because / \% \uparrow$ & $\%+\varphi_{\Delta}$ & . & $-\cdot / / Y T$ & 年 & ./994 & $\cdot / r \cdot \Delta$ & 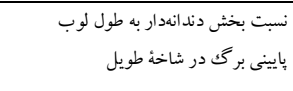 \\
\hline 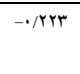 & $-\cdot / / r \mid$ & $/ / 4 \mathrm{Fv}$ & $\begin{array}{c}.19 \mathrm{~V} \cdot 00 \\
-\end{array}$ & $\% .91$ &.$\% \%$ &.$/ 1 Y 9$ & . / YVYF & $--/ / 1 \Delta$ & $\cdot / 4 r \cdot{ }^{\circ}$ & .1 .99 & $\cdot /$ THF & تعداد دندانه بركى در شاخهُ طويل \\
\hline$-\cdot / M$ &.$- / .19$ & . TYFa & . ror &.$- / 19$. &.$/ \Delta r$ & $-\cdot / / \wedge 9$ & $\cdot / \mathrm{rVT}$ & $-\cdot-11 . \Delta$ & $-\cdot \cdot /$ MA & $-\cdot \cdot / \cdot v$ & $-\cdot / / F r$ & محل بريد كى بايينى بركى در شاخة طويل \\
\hline.$/ .99$ &.$/ 1 \% 4$ &.$/ \% \mathrm{Fr}$ & $-\cdot / \cdot \mathrm{W}$ &.$/ 101$ &.$/ 119$ &.$/ / F T$ & $-\cdot / / m$ &.$/ 119$ & $-\cdot / 114$ & $-\because / . r Y$ & $-\cdot / / \wedge \cdot$ & طول دمبر كث در شاخة طويل \\
\hline.$- / .14$ & 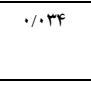 & $1 / .99$ & $-r / r a r$ & $-\% / \%$ &.$- / . r r$ & $\% \cdot A r$ &.$/ .49$ & $\% \cdot v_{\Delta}$ & $\%$ & .1 .99 & 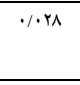 & شسبت طول دمبركَ به طول بركَ در \\
\hline$\%+49$ & $-* / . \vee 4$ &.$/ 19$. & $-8 / 119$ &.$/ \% \cdot 1$ & $-r / / V Y$ & $-\cdot \cdot / \cdot 1$ & $-\pi / 10$. & $-\cdot / \cdots$ & $-\because / \cdot v r$ & . /TYD & \% rr & طول خار در شاخهُ كو تاه \\
\hline.$- / . \Delta r$ & $-\cdot / r A \Delta^{*}$ &.$/ 1 \Delta r$ & $-\cdot \pi / 1$ &.$/ \% 99$ & $\% r$ & . $/ 1 \Delta \mathrm{V}$ &.$- / \mathrm{rav}$ &.$- / \% 11$ & $-\cdot / 490$ & $\% / \Delta r$ & $-\cdot / r \cdot 4$ & طول بركَ در شاخة كو تاه \\
\hline$-\cdot / 1 \Delta \mathrm{rr}$ & $-\cdot / F Y 9^{\circ}$ &.$/ / r$. & .149 .00 & . & $-\cdot \cdot \cdot \Delta r$ &.$/ 199$ & -.1 .99 & $-\because / 101$ & $-\cdot / \cdot v 1$ & $\% \cdot v r$ & $-\cdot / . \Delta 9$ & عرض بركث در شاخُٔ كوتاه \\
\hline$-\cdot / r \cdot 1$ & $-\cdot / \cdot$ YAV &.$/ \Delta Q F$ & $-r / R \Delta F$ & $\% M$ & -/IV9 & 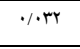 & $1 / .09$ & $-0 / 4 T^{\circ}$ & $1 / \% 4$ & $-0 / 119$ & $-\cdot / r \mid$ & تعلداد لوبهاى بركث در شاخةُ كو تاه \\
\hline$\% r r$ & $-\% \cdot \Delta$ &.$/ 149$ & $-\pi / 49$. & $\% / .9$ & $\% r r$ & . /TFF &.$/ N T$ & $-\cdot / 1 \Delta \Delta$ & $\% \cdot \Delta r$ & $\% \mathrm{Fr}$ & \% r rq & در شاخد كول باه عرض لوب يا ياينى بركث \\
\hline$-\cdot / \cdot 1 \wedge$ & $-* / \cdot \wedge$ &.$/ Y Y A$ & $-\cdot / T Y F$ &.$- / 194$ & 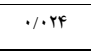 & ./FF. & $\cdot / r r$ & $\%$ &.$/ r i r$ & $-8 / 9 r$ & .1 .90 & عمق بريدگى بايينى بركَ در شاخة كوتاه \\
\hline$-\cdot / 111$ & .1 .99 & - /AN & $-\cdot /$ /rq & $-\%$ - & $-\cdot / \cdot v$ & .11 .4 & ./IVA & |r| & . &.$/ \mathrm{WW}$ & $\cdot / \mathrm{TV} \mid$ & بركى در شاخد كون تاه دار به طول لوب بايينى \\
\hline$-\pi / \% 99$ & $\% \cdot V Y$ & 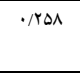 & 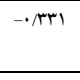 & $-\% \cdot M$ & $\cdots / \cdots$ & $1 / 9 \Delta$ & . $/ \pi r$. & $-\cdot / / N F$ & 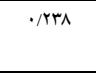 & $-\cdot / / 1 \wedge$ & $\cdot / 1 .$. & كوتلاه دندانه لوب بايينى بركث در شاخة \\
\hline$-\cdot|\& \Delta|^{\circ}$ & $-\cdot / F \Delta F^{\circ}$ & - /YFG & $-\because / T \backslash \Lambda^{\circ}$ & $\% \cdot .1$ &.$/ 1.1$ &.$- / . r r$ & $\cdot \pi / f$ & $-\pi / \mu r$ & $\cdot / r \cdot v$ & $-\cdot / 19$ & $-\cdot / \cdot v$ & محل بريدگى يايينى بركى در شاخهُ كوتاه \\
\hline$-\pi / \% \uparrow$ & $-* / . v$. & 11.49 & $-\cdot \mu F v$ & $\%+4$ & .1 .94 & . & $-\cdot / 194$ & $-\because / 1 M$ & $-0 / .91$ & 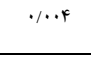 & $-\cdot / 11 \Delta$ & طول دمبر كُ در شاخدُ كوتاه \\
\hline$-\cdot / / 1 f$ & $-\cdot / \cdot \wedge$ & $-\cdot / / r$ & $-\cdot r \cdot r \cdot r$ & $-\cdot \cdot / \cdot r$ & $\cdot / \cdot v r$ &.$/ 194$ & $-\cdot / 1149$ & $-\because / . \Delta$ & $-\cdot \% \cdot r \Lambda$ & $-\cdot / 11$ & $-\cdot / / 1 \mathrm{~V}$ & نسبت دمبر گَى به طول برگى در شاخه \\
\hline$\% \cdot \mathrm{vV}$ &.$/ 149$ & $\% \cdot \wedge r$ & $-\cdot /$ - YYQ & $\%+\% q$ & $-\cdot / T I V$ &.$/ 1 V^{\prime}$ &.$/ \% Y$ &.$/ 119$ & $\cdot \cdots \Delta$ & - / YFY &.$/ 194$ & طول بركَ در شاخة كلدهنده \\
\hline$-\cdot / 194$ &.$/ 1 F 1$ & $-\because / \% \wedge$ & $-\cdot / .94$ & $-\cdot / \cdot \% \mathrm{~V}$ & $-\cdot / K F r$ & $\cdot / 1 \cdot v$ & $-\cdot / \cdot v r$ &.$/ 10 r$ &.$/ \Delta \Delta$ & $\cdot / 491$ & $\cdot / r W$ & عرض بركى در شاخة كل دهنده \\
\hline$-\cdot / / r r$ & $-\cdot \% \cdot \cdot 9$ & $\% / 91$ & $-\because / \Delta r$ & 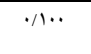 & $-\cdot / \cdot 14$ & $-\cdot / 194$ & (4) & $-\cdot / 1 \cdot r$ & $\cdot / 1 \cdot r$ & $\cdot / \cdot \wedge f$ & $\cdot / \cdot \Delta \Delta$ & تعلداد لوب بركّ در شاخة كل دهنده \\
\hline$-\because / \%$ r &.$/ 119$ & $\cdot / r / f$ &.$-- / .9 r$ &.$/ 11$. & $-\cdot / \cdot 19$ &.$/ \cdot \Delta f$ & $\cdot / \cdot \mathrm{WV}$ & $-\cdot / / \mathrm{Vr}$ & $-\cdot \cdot / \Delta r$ & $\cdot / \cdot v^{q}$ & $\% \cdots$ & 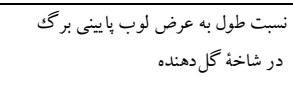 \\
\hline 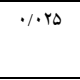 & $. / \pi T+0$ & $\%+4 F$ & $-r / / V \wedge$ & $-\% / 11$ & $-r / Y \mathrm{VV}$ & $-0 / .49$ &.$/ 194$ & $\%+r$ & . $/ R F V$ &.$/ 10^{\circ}$ & $\cdot / R \Delta 9^{\circ}$ & دهمق بريدَّى بايينى بركى در شاخة كل - \\
\hline$-\cdots / \% q$ & . RYA & 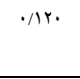 & $-* / \cdot \Delta$ & -1.90 &.$/ \pi 1 \Lambda^{\circ}$ &.$/ r \Lambda$. & $-\cdot / R T Y$ & $-\cdot / / T V$ & $-\cdot / \pi 99^{\circ}$ & $-\because / \mathrm{rVq}$ & $-2 / \pi 10^{\circ}$ & 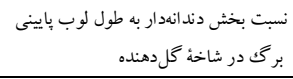 \\
\hline$-\because / M A F$ & $.1 \% 9$ & $\cdot / / Y I$ & $-\cdot / / r m$ & $-\cdot / 1 Y q$ & $-\cdot / \pi \psi$ & $-.1 .9 \mathrm{~V}$ &.$/ r Y 9^{\circ}$ & $-\cdot / 1 / r$ & $\cdot / 4 W^{20}$ &.$/ Y$. &.$/ 4 I^{20}$ & تعلداد دندانه لوب بيايينى بركّ در شاخة \\
\hline$-\cdot / N Y$ & $\cdot / r \cdot F$ & $-\cdot / \pi T H$ & $\cdot / M F V$ & $-* / \times 1$ & $-\circ / .9$ & $\cdot / \cdot v \Delta$ & $-\cdot / / \mathrm{FT}$ &.$/ 100$ & $-\cdot / / r$. &.$/ 1 \% \Delta$ &.$/ \% V$ & 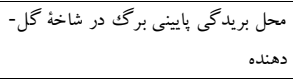 \\
\hline $1+49$ & . & $-\cdot / / r \mid$ &.$/ 149$ & $.1 \cdots$ &.$- / . Y Q Y$ & 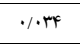 & -.1 .94 &.$/ 194$ & $-\cdot / \cdot \mathrm{VV}$ &.$/ 49^{\circ}$ &.$/ 19 \mathrm{~V}$ & طول دمبر گك در شاخة كل دهنده \\
\hline
\end{tabular}




\begin{tabular}{|c|c|c|c|c|c|c|c|c|c|c|c|c|}
\hline$\cdot / \Gamma \wedge$ & $\cdot / 19 Y$ & $-\cdot / 190$ & $\cdot / 101$ & -.1 .49 & $-\cdot / 1 \otimes \wedge$ & $\cdot / \cdots$ & $-\because / .4 F$ & $\cdot / / \Delta r$ & $-\cdot / \cdot 14$ & $\cdot /$ /YYY & - / /FY & نلسبت دمبركَ به طول بركث در شاخة \\
\hline$--\cdot / \wedge \Delta \Delta$ &.$- / .4 r$ & $-\cdot / r V \mid$ &.$-- / \mu \cdot 4$ &.$- / 191$ &.$/ \Delta \cdot \Delta$ &.$/ 111$ & $\cdot \mathrm{NM}^{\circ}$ &.$- / 911$ & $\cdot / 4 \Delta q$ &.$- / 94 \mathrm{Fr}$ & $-2 / . .9$ & طول كلآذين \\
\hline . $/ r \Delta \Delta$ & $.194 \pi$ &.$/ / V I$ & $-\cdot / / 11$ & $-\because / 4 r$. & $-\cdot / \mathrm{IVV}$ & $\cdot / 101$ & $\cdot / * \cdot v$ & $\cdot /$ /TY9 & $\cdot / / Y I$ &.$/ \mu r$ &.$/ 491$ & تعداد گل ها \\
\hline$-\cdot / \Delta \cdot f$ & $-\cdot / 19$ & $\cdot r \cdot v$ & $. / 9 . r$ & $-\cdot / A \wedge r$ & $\cdot / \mu F r$ & $\cdot \cdot / / 9 V$ &.$/ \pi r$. & $\cdot / \cdot v 9$ & $\cdot / 49 \Delta$ & $-\cdot r \cdot 1$ & $-\cdot / r v r$ & طول دمخل \\
\hline$\%$ &.$/ 1 f$. & $-\cdot \pi \varphi v$ & $-* / . v \pi$ & $-\cdot / N T^{\circ}$ & . $/$ /NI &.$/ \pi \mathrm{IV}$ & 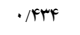 &.$/$ TFF & . $/$ THD & $-\cdot / 4 Y 4$ & $-\cdot / \cdot r r$ & طول براكته \\
\hline.$- / 4 \% 9$ & -.11 .4 &.$/ 144$ & $\cdot / \mathrm{FVY}$ & $-\cdot / \Delta \Delta q$ & . rafa & $-\cdot / \% \mathrm{Fr}$ &.$/ r r$ & $\cdot /$ TFF & $\because \times \mathrm{va}$ & $-\cdot / K F \Delta$ & $-\cdot \pi Y T$ & عرض راكته \\
\hline . /AN &.$/ 194$ & $-\cdot / \Delta F Y$ & $-\cdot \mu \cdot r$ & $\%+4$ & $-\cdot / \cdot M$ & $\% \Delta v$ & $\cdot / K F$ & $-\cdot / 1 F 4$ & $-\cdot / 499$ &.$/ 4 r$ & D/YAY & نسبت طول به عرض بر اكته \\
\hline$-\cdot \cdot / \mathrm{NA} \cdot{ }^{*}$ & $-\cdot / 190$ & $\% \cdot \wedge r$ & $\cdot v \cdot v^{6}$ & $-\cdot r \mu \mathrm{AV}$ & $\cdot / 499$ & $-\because / F Y V$ & $\cdot / \Delta \Delta Q$ & $-\cdot / r \Delta r$ & 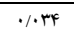 & $-\because / \Delta F F$ & $-\cdot / 49 \wedge$ & طول هييانيوم \\
\hline .11 .0 & $\cdot / \mathrm{FV}$ &.$/ Y 19$ &.$/ .45$ &.$- / 90 \mathrm{~V}$ & $-\cdot / 1 r$ & $-\cdot / / r r$ &.$/ 491$ & $\cdot /$ TFY & $\cdot / \pi r$ &.$- / .+q$ & $\cdot / \& 94$ & طول كاسبرگث \\
\hline.$- / .44$ & $-\cdot /$ rav & $-\cdot / \pi T$ & $-\because / 4 \Delta \mathrm{V}$ &.$/ Y A 1$ &.$/$ Fva &.$/ \% \Delta r$ &.$/ T T r$ &.$- / 4 \% A$ & . IFF & $-\cdot|\psi|+\mid$ & $-. / 4+9$ & عرض كاسبركث \\
\hline$\cdot / 1 \cdot v$ & . Nar" & .1994 & $\cdot / \pi \wedge 9$ & $-\cdot / \Delta \psi \Delta$ & $-\because / \Delta \% 9$ & $-\cdot / \% \mathrm{~V}$ & $\cdot \pi / 1$ & $\cdot / \Delta \Delta 9$ & $\cdot / \mu 4+$ & $\cdot / \mathrm{Fr} \cdot$ &.$/ 911$ & نسبت طول به عرض كاسبر گث \\
\hline$-\cdot / N I^{*}$ &.$- / \% \wedge 9$ &.$/ \Delta F$. &.$/ \wedge r Y^{\text {so }}$ & 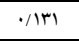 &.$/ Y \Delta \Delta$ &.$- / 1 \wedge 9$ &.$- / / \mathrm{V} 9$ &.$- / 1 V_{\Delta}$ & $-\cdot / \mu \Lambda V$ & $-\cdot / 199$ & $-\cdot / \Delta 9 \mathrm{~V}$ & طول كلبر كث \\
\hline-.1919 & - rrar & .1994 & $\cdot / \Delta \mathrm{Fr}$ & $\cdot / r \cdot \Delta$ & $\cdot / F \wedge 1$ &.$- / / \Delta \Delta \Delta$ &.$/ 11 \%$ & $-\cdot / k r \mid$ &.$- / 191$ & $-\cdot / 49 v$ & $-\cdot / \Delta \cdot \Lambda$ & عرض گلبرگك \\
\hline$\cdot N \cdot \cdot{ }^{\circ}$ & $\cdot / \Delta F \mid$ &.$/ \Delta \mathrm{VA}$ &.$- / 411$ &.$/ 111$ & $-\cdot / \Delta \cdot v$ & $\cdot / r M$ & $-0 . / 4 \cdot 4$ & $\cdot / \Delta 4 Y$ & $\cdot / 1 \cdot 1$ &.$/ 491$ & $\cdot /$ Fva & تعداد بِرجم \\
\hline$-\cdot / \cdot M$ & $\% M$ &.$- / . r r$ & 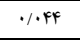 & $-\cdot / / T 9$ & .119. &.$/ 1 \mathrm{~V}$ & $.1 . \Delta 0$ & $-\cdot / 1 \cdot r$ &.$/ 10$ & $-\cdot / Y Y Y$ & $-\cdot / 191$ & طول ميوه \\
\hline$-.1 . .4$ & $\cdot / N r \wedge$ & $\% r$ & $-.1 . .4$ & $-\cdot / 1$ & . TOF & $\cdot / r \cdot v$ &.$/ \mu F$ &.$- / . \Delta \wedge$ & $\% 11$ & $-0 / \mathrm{TVA}^{\circ}$ & $-\cdot / r \cdot v$ & قطر ميوه \\
\hline.$- / 1.9$ & $-\cdot / \cdot \Delta \wedge$ & $-\cdot / \cdot r v$ & 1.4. & $.1+4$ & $-\cdot / / T F$ &.$- / . v r$ &.$- / .49$ & $-\cdot / \cdot \mu_{\Lambda}$ & $\% \cdot r$ & 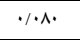 &.$/ .14$ & نسبت طول به قطر ميوه \\
\hline.$/ 1 \mathrm{HF}$ &.$/ T H F$ & .11 .9 & $\cdot \pi r F$ & $\% \mathrm{vV}$ & $\% / 11$ & $-\cdot / / M$ &.$/ / F T$ &.$- / . \cdot 4$ &.$- / .11$ &.$- / . r t$ & $-\cdot / / m \mid$ & طول كاسبر كى ميوه \\
\hline.$/ \mathrm{TFF}$ & $\cdot / \mathrm{WV}$ &.$/ 1 T \mathrm{TV}$ &.$\mu k r^{s o}$ &.$/ 199$ & .1 .94 & $-2 / .+1$ & $-\cdot / \cdot r$ &.$- / Y \Delta 1$ & $-\cdot / 119$ &.$/ r r$ & $-\cdot / 109$ & عرض كاسبر كث ميوه \\
\hline$\% \Delta \Delta$ & $\cdot / r$ & $-\cdot / l \uparrow V$ & $\cdot /$ TFF & -.1 .94 &.$/ 1 \mathrm{TV}$ & $-\cdot / / r \mid$ & $\cdot 1 \cdot \mathrm{rV}$ & $\% \mathrm{Fr}$ &.$- / \cdot 19$ &.$- / .9 \mathrm{~V}$ &.$- / .94$ & تعلداد خامهها \\
\hline$-\cdot / r \cdot \Lambda$ & $-\cdot / 199$ & .11 .0 & $\%+\mathrm{kr}$ &.$/ T \Lambda$ &.$/ 11$ & $-\bullet / \cdot \vee$ &.$- / .14$ &.$- / 1.9$ &.$/ \% \Delta$. & -.1 .91 &.$- / . \pi T$ & تعداد شيار سطح يشتى دانه \\
\hline$-.1 . \Delta 9$ & $-\cdot / 11$. & $-\cdot / Y Y 9$ & $. \%+\mathrm{KF}$ & $-\cdot / \cdot r$ &.$/ \% \mu$ & $-\circ / \%$ &.$- / 114$ & $\% . r$ & $\% 14$ & $-\circ / . \Delta$. & $-0 / \% 4$ & تعداد شيار سطح بهلويى -شكمى دانه \\
\hline & & & & & & & & & & & & صفات كيفى \\
\hline$\cdot / r F$. & .1 .9 & $\cdot 1 \cdot 19$ & $.149 V^{\circ}$ &.$- / \mu \cdot 9$ & $-0 /+\% 1$ & . &.$/ \cdot A \mathrm{~A}$ &.$/$ IVF & -.1 .90 & $.1 . \mathrm{FF}$ & $-\odot / \%$. & شكل كاسه در حالت كل \\
\hline$-\cdot / 191$ & $-\cdot / 199$ & $\cdot \% \cdot v r$ & .1 .9$. &.$/ 110$ &.$-- / 194$ & $-\cdot / 199$ &.$- / .+4$ & -.1 .94 & $-\cdot \cdot / \cdot r$ & $\because \cdot \Delta f$ &..$- / 14$ & شكل ميوه \\
\hline$-\because \% \mu \mathrm{V}$ & $-\because / . \triangle F$ & $-\cdot / F V^{* 06}$ &.$/ 11 f$ & $-\circ / \% \wedge$ & $-\cdot \cdot / \cdot \mathrm{VV}$ & $-.1 .+4$ & $-\cdot / / \Gamma \Lambda$ &.$/ 1 \Delta \mathrm{V}$ & $\% \cdots$ & $\cdot 1.9 \Lambda$ & $\cdot / \cdot 11$ & رنگك ميوه \\
\hline$-\cdot / 111$ &.$/ 4.1^{\circ}$ &.$/$ ror & $-\cdot+/ \cdot r$ &.$/ 1 \mathrm{IV}$ & $-\cdot / 190$ & $-\cdot \cdot / \mathrm{Fr}$ &.$/ 11 r$ & 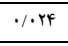 &.$/ 1 V^{4}$ & $\cdot / r \Delta \Lambda$ &.$/ 49 \mathrm{~V}^{\circ}$ & يوشش سطح ميوه \\
\hline-.1 .90 & -.1 .91 & $-\cdot / r W^{\circ}$ & $-\cdot / / \Lambda$. &.$- / \%$ & $\% \cdot W$ &.$/ 4 r \cdot 0$ &.$- / Y \varphi$ & $\cdot / \cdot$. & $-\cdot / \mathrm{NV}$ & $-\cdot / . r \Delta$ & $-\cdot / / r r$ & شكل قاعده ميوه \\
\hline
\end{tabular}

در تغييرات ريختشناسى گياه نشان مىدهد. مقايسٔ اين تحقيق با

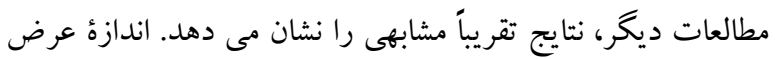

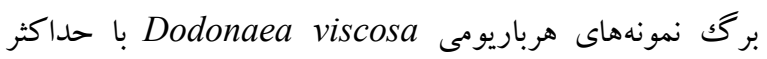

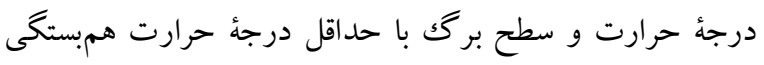

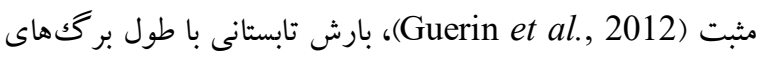
Salix herbacea L.

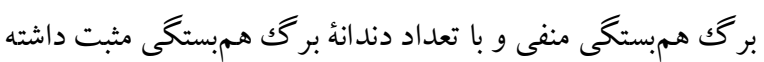

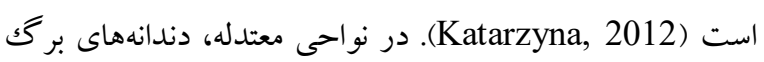

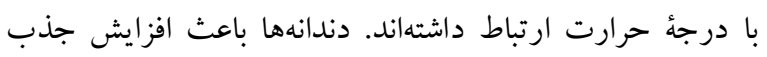

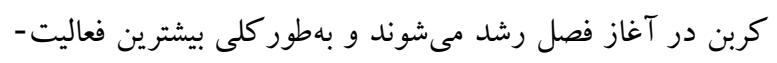

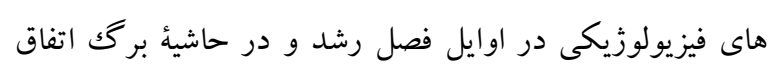

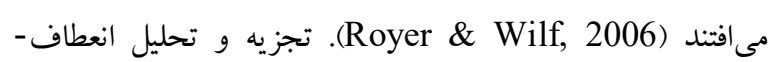
يذيرى فنو تييى در واكنش به باد بيجيده است، و واكنش هاى كياه

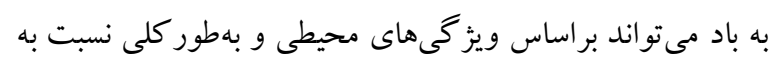

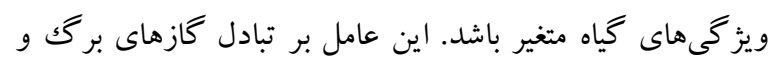

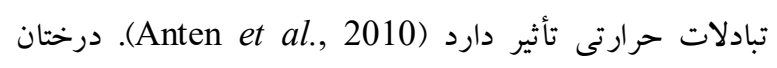

مختلف، ازجمله صفاتى هستند كه از ديرباز در كانون توجه كياه-

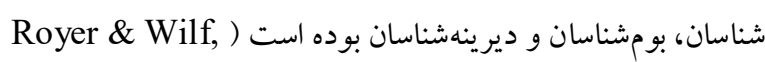
2006; Zarafshar et al., 2009; Anten et al., 2010; Guerin et al., 2012; Katarzyna, 2012; Chitwood, تأن تأثير حالتهاى اقليمى متفاوت، از خود نشان تنوع مىدهند، برخى

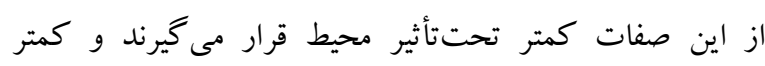

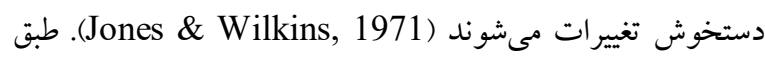

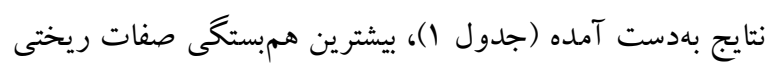

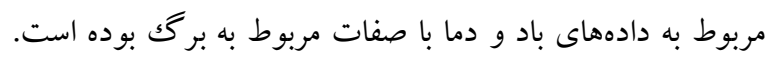

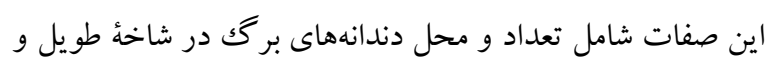

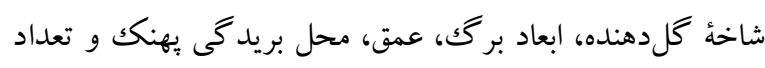

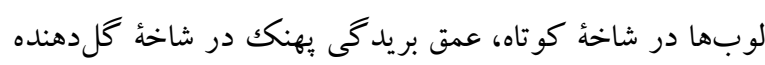

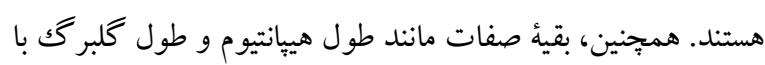

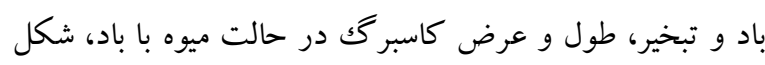

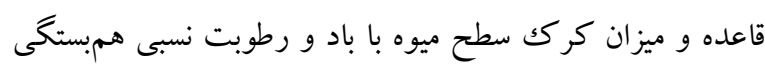

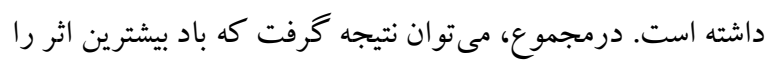


C. ucrainica ،C. eriantha Pojarkova مايى مانند , C. dikmensis Pojark. ‘C. persica Pojark. ‘Pojark. C. meyeri ا بر ادف كرده است C. stankovii Kossych (Christensen, 1992). ازطرف ديخر، صفاتى را كه بوزاركوا براى جداسازى گونههاى نزديكك به C. meyeri به كار برده است، شامل عمق بريدگى بايينى در برگكهاى شاخههاى گلدهنده، محل بريدگى بايينى برگك، تعداد لوبها، نسبت طول به عرض لوب يايينى بركَ در شاخهُ گل دهنده (شكل لوب)، تعداد دندانه هاى لوب بايينى برگك و محل قرارگيرى دندانهها بوده است

.(Pojarkova, 1939)

طبق نتايج اين تحقيق (جدول ())، از صفات بيش كفته، عمق بريدگى بايينى بر گك، محل دندانها و تعداد دندانهها در شاخههاى كلدهنده با دادههاى مربوط به دما همبستگى داشتهاند و صفاتى صنى مانند تعداد لوب بركى در شاخه كل مدهنده، نسبت طول به عرض تر

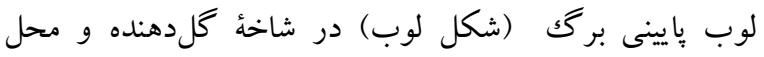

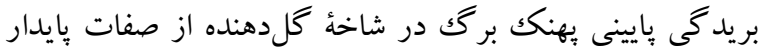
در C. meyeri بوده و همبستگى آمارى با دادههاى اقليمى نداشتهاند. هر گاه صفات همبسته با ويز گى هاى اقليمى را قوىترين صفات جداكنندة گونهها در نظر بـيريم، نظر كريستنسن بذيرفتنى خو اهد بود، و هر كاه صفات غيرهمبسته با ويز گى هاى بومشناختى بيشنظر باشد، صفات جداكندهُ گونها، كه يوزاركوا درنظر داشت، منطقى است. بهنظر مىرسد مطالعهُ بيشتر گونههاى مذكور در طبيعت و در محيطهاى بومشناختى مختلف، قادر به تأييد صحت نظريه كريستنسن يا بوزار كوا است.

سياسگزارى

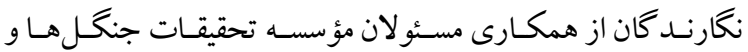
مراتع كشور و هربـاريوم مركـىى دانشـاه تهـران جهـت اسـتفاده از نمونههاى هرباريومى قدردانى مى كنند.

\section{REFERENCES}

Anonymous. 1983-2010. Meteorological calendar of Iran. I.R. Meteorological Organization, Tehran.

Anten, N.P., Alcalá-Herrera, R., Schieving F. and Onoda, Y. 2010. Wind and mechanical stimuli differrentially affect leaf traits in Plantago major. - New Phytol. 188: 554-64.

Chitwood, D.H. 2016. Climate and developmental plasticity: interannual variability in grapevine leaf
بلوط، بركتهايى كه داراى لوبـهاى كموبيش عميقتر هستند،

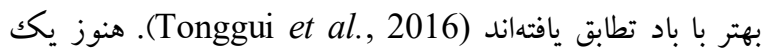
مدل مورفومتريك يكهارجهه تكاملى رشد و نمو و تأثير ات زيست محيطى روى شكل برگك وجود ندارد (Chitwood, 2016). در تحقيق حاضر، باد فقط با تعداد دندانه در برگكهاى شاخههاى طويل و در شاخههاى كوتاه با ابعاد برگك همبستگى نشان داد.

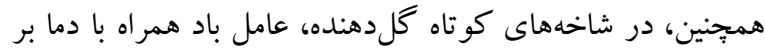
عمق بريدگى بهنك بر گك و محل دندانهها در شاخه هاى گل دهنده مرتبط است. علاوهبر صفاتى كه با اقليم همبستگى دارند، صفات ديخرى نيز وجود دارند كه هيج گونه ارتباطى با دادههاى اقليمى نداشتهاند. اين صفات، بهغير از تعداد دندانها، شامل تمام صفات

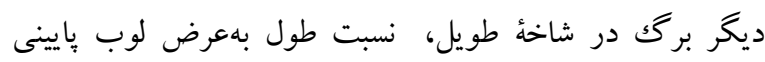

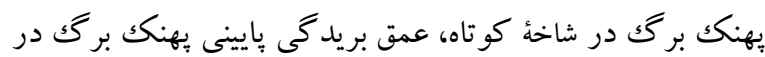

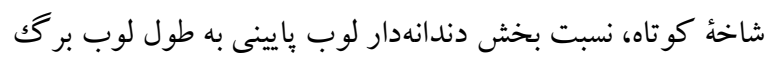
در شاخهُ كوتاه، طول دمبرگك شاخهُ كوتاه، نسبت دمبر گك به طول

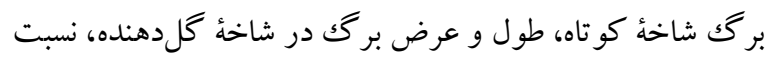

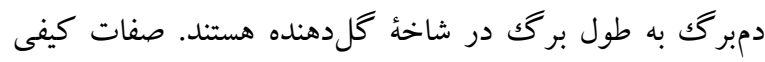
يايدار در ميوه نيز شامل كاسبر گك بر گشته و شكل مثلثى آن، رنگك كوشت و رنگك برونبر ميوه است. مهمترين صفاتى كه C. meyeri را از بقية گونهاى سرده زالزالكى تفكيك مى كنند، تعداد دانه يا خامه و حضور كركى متراكم در شاخههاى جوان و قاعده جهارگوش ميوه است Pojarkova, 1939; Riedl, 1969; Christensen, 1992; ) Khatamsaz, 1992 (اين صفات بهغير از قاعدهُ ميوه، در تمام جمعيتهاى بررسى شده C. meyeri ثابت بوده است. در بيشتر منابع تاكسونوميكى مربوط به سرده Crataegus، ويز گمىهاى مربوط به بركگهاى شاخه هاى طويل از صفات متمايز كننده گونهها Poajarkova, 1939; Riedl, 1969; ) بهشمار نمى آيند Khatamsaz, 1992; Donmez, 2004, 2007; Christensen, 2013; Hamzeh'ee, 2013; Hamzeh'ee et (al., 2013, 2015, 2016 (اين بركها در اكثر گونهها بسيار شبيه به يكديخر هستند و ازنظر ريختى تقريباً يككنواخت هستند. تحقيق حاضر نيز نشان مىدهد كه عوامل اقليمى كمترين همبستخى را با صفات بر گكهاى شاخههاى طويل داشته است (جدول (). براساس نظر Christensen (1992) صفات ريختى گونه meyeri 
morphology. - Plant Physiol. 170: 1480-1491.

Christensen, K.I. 1992. Revision of Crataegus section Crataegus and Nothosect. Crataeguineae (RosaceaeMaloideae) in the Old World. - Syst. Bot. Monogr. 35: 1-199.

Dönmez, A.A. 2004. The genus Crataegus L. (Rosaceae) with special references to hybridization \& biodiversity in Turkey. - Turk. J. Bot. 28: 29-38.

Dönmez, A.A. 2007. Taxonomical notes on the genus Crataegus L. (Rosaceae) in Turkey. - J. Linn. Soc. 155: 231-240.

Guerin, G.R., Wen, H. and Lowe, A.J. 2012. Leaf morphology shift linked to climate change. - Biology letters 8: 882-886.

Hamzeh'ee, B., 2013. Taxonomical studies on the genus Crataegus L. (Rosaceae) in Iran. - Ph.D. thesis. Scho-ol of Biology, University of Tehran. pp 350.

Hamzeh'ee, B., Attar, F., Assareh, M. H., Maassoumi, A.A., Kazempour Osaloo, S. and Christensen, K.I. 2013. Taxonomic notes on Crataegus, ser. Crataegus, subser. Erianthae (Rosaceae), new species and record, using morphology and micromorphological evidence. - Nord. J. Bot. 31: 001-012.

Hamzeh'ee, B., Attar, F., Zielin'ski, J., Assareh, M.H. and Mozaffarian.V. 2015. Do species of Crataegus sect. Sanguineae occur in Iran? - Nord. J. Bot. 33: 414-420.

Hamzeh'ee, B., Attar, F., Assareh, M.H., Maassoumi, A.A. and Kazempour Osaloo, S. 2016. Comparative micromorphological characteristics of lower leaf epidermis and seed surface in two series of Crataegus L. (Rosaceae) and their taxonomical role. - Iran. J. Bot. 22: 126-137.

Jones, D.A. and Wilkins, D.A. 1971. Variation and adaptation in plant species. - Heinemann Educational Books Ltd, London, UK, 184 pp.

Jones, S.B. and Luchsinger, A.G. 1979. Plant Systematics. - McGraw-Hill, New York, 292 pp.

Katarzyna, M. 2012. Variation of leaf shape of Salix herbacea in Europe. - Plant Syst. Evol. 298: 15971607.

Khatamsaz, M. 1992. Rosaceae. -In: Assadi, M. et al. (eds.), Flora of Iran. 6: 247-267. R.I.F.R. Tehran.

Mabberley, D.J. 1997. The plant book: a portable dictionary of the vascular plants. 2nd ed. Cambridge University Press.

Phipps, J.B. and Muniyamma, M. 1980. A taxonomic revision of Crataegus (Rosaceae) in Ontario. Canad. J. Bot. 58: 1621-1699.

Pojarkova, A.I. 1939. Crataegus L. (Rosaceae). - In: Komarov, V.L., Yuzepchuk, S.V. (eds.): Flora of the USSR, vol. 9: 317-356. Bot. Inst. Akad. Nauk SSSR, Moscow-Leningrad.

Riedl, H. 1969. Crataegus L. (Rosaceae I) - In: Rechinger, K.H. (ed.): Flora Iranica, Lfg. 66: 49-65 - Akad. Druck-und Verlagsanstalt, Graz.

Royer, D.L. and Wilf, P. 2006. Why do toothed leaves correlate with cold climates? gas exchange at leaf margins provides new insights into a classic paleotemperature proxy. - Int. J. Plant Sci. 167: 1118.
Tonggui, W., Zhang, P., Zhang, L., Wang, G.G. and Mukui, Y. 2016. Morphological response of eight quercus species to simulated wind load. - PLoS One 11: $1-14$.

Zarafshar, M., Akbarinia, M., Yosefzade H. and Sattarian, A. 2009. Leaf and seed morphological trait in Celtis australis L. in different geographical condition. - Iranian J. Rangelands and Forest Plant Breed Genet Res. 17: 88-99.

$* * * * *$

How to cite this article:

Hamzeh'ee, B., Nobakht, M., Asri, Y. and Bakhshi Khaniki, Gh. 2018. Evaluation of morphological changes of Crataegus meyeri Pojark. in relation to some climatic parameters in Iran. - Nova Biologica Rep. 4: 320-328.

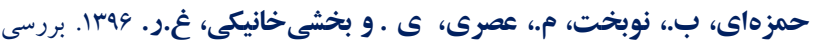

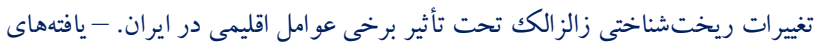

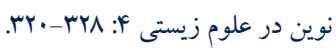

